\title{
Mood Reactivity Rather Than Cognitive Reactivity Is Predictive of Depressive Relapse: A Randomized Study With 5.5-Year Follow-Up
}

\author{
Gerard D. van Rijsbergen and Claudi L. H. Bockting \\ University of Groningen \\ Philip Spinhoven \\ Leiden University and Leiden University Medical Center, \\ Leiden, the Netherlands \\ Henricus G. Ruhé \\ University of Amsterdam and University Medical Center \\ Groningen, Groningen, the Netherlands
}

\author{
Huibert Burger \\ University Medical Center Groningen, University of Groningen, \\ Groningen, the Netherlands
}

Maarten W. J. Koeter

Academic Medical Center, University of Amsterdam, Amsterdam, the Netherlands

Steven D. Hollon

Vanderbilt University

\author{
Aart H. Schene \\ Academic Medical Center, University of Amsterdam, Amsterdam, the Netherlands
}

\begin{abstract}
Objective: The current study examined whether cognitive reactivity, cognitive extremity reactivity, and mood reactivity following mood provocation predicted relapse in depression over 5.5 years. Additionally, this study was the 1st to examine whether changes in cognitive reactivity and mood reactivity following preventive cognitive therapy (PCT) mediated the preventive effect of PCT on relapse. Method: One hundred eightyseven remitted recurrently depressed outpatients were randomized over treatment as usual (TAU) versus TAU + PCT with 5.5-year follow-up. Relapse in depression was assessed with the Structured Clinical Interview for DSM-IV Axis I Disorders (Spitzer, Williams, Gibbon, \& First, 1990). Results: Mood reactivity predicted time to relapse over 5.5 years. We found no evidence that cognitive reactivity was a risk factor for relapse in depression. Moreover, unprimed dysfunctional beliefs predicted relapse directly. There was no indication of mediation by changes in cognitive reactivity (including extremity of the beliefs and unprimed beliefs) or mood reactivity on the preventive effect of PCT. Further, explorative analyses revealed that increases in cognitive and mood reactivity over time also predicted time to relapse. Conclusions: Our findings highlight a need to focus on mood reactivity instead of beliefs as a risk factor for relapse in depression. Similar to a previous study, we found no indications that cognitive therapy after remission reduced dysfunctional beliefs, cognitive reactivity, or extremity. Future studies should examine cognitive reactivity and mood reactivity in daily life as predictors of relapse.
\end{abstract}

Keywords: major depressive disorder, dysfunctional belief, cognitive reactivity, relapse prevention, working mechanism cognitive therapy

Supplemental materials: http://dx.doi.org/10.1037/a0032223.supp

This article was published Online First March 11, 2013.

Gerard D. van Rijsbergen and Claudi L. H. Bockting, Department of Clinical Psychology, University of Groningen, Groningen, the Netherlands; Huibert Burger, Department of Epidemiology and Interdisciplinary Center for Psychiatric Epidemiology, University Medical Center Groningen, University of Groningen, Groningen, the Netherlands; Philip Spinhoven, Institute of Psychology, Leiden University, Leiden, the Netherlands, and Department of Psychiatry, Leiden University Medical Center, Leiden, the Netherlands; Maarten W. J. Koeter, Department of Psychiatry, Academic Medical Center, University of Amsterdam, Amsterdam, the Netherlands; Henricus G. Ruhé, Department of Psychiatry, Academic Medical Center, University of Amsterdam, Amsterdam, the Netherlands, and Department of Psychiatry, University Medical Center Groningen, University of Groningen, Groningen, the Netherlands; Steven D. Hollon, Department of Psychology, Vanderbilt University; Aart H. Schene, Department of Psychiatry, Academic Medical Center, University of Amsterdam, Amsterdam, the Netherlands.

We declare no conflicts of interest. The International Standard Randomized Controlled Trial Register Identifier for this article is ISRCTN68246470. This research is funded by The Netherlands Organisation for Health Research and Development (ZonMw; Prevention: 2200.0029). We are most grateful to the patients of our study. In addition, we express our appreciation to the participating psychiatric sites for their recruitment efforts, and to the following therapists for conducting the cognitive therapy: Willemijn Scholten, Swanny Wierenga, Mieke van der Rijken, Ruud Kol, Birgitta Schalken, Els Loeb, Vera van der Kraan, and Annemarie Fouwels. We also thank Jan Mars, our interviewers, the independent raters, and specifically Irene Visch for assistance with data management and support. Finally, we thank Lonneke van Tuijl for her helpful suggestions on an earlier version of this article. The following colleagues contributed to the Depression Evaluation Longitudinal Therapy Assessment (DELTA) study: Hanneke Assies, Claudi Bockting, Mascha ten Doesschate, Jochanan Huyser, Anja Lok, Maarten Koeter, Guido Nabarro, Henricus Ruhé, Aart Schene, Philip Spinhoven, Ieke Visser, Ellie Wekking, and Luuk Wouters.

Correspondence concerning this article should be addressed to Claudi L. H. Bockting, University of Groningen, Department of Clinical Psychology, Grote Kruisstraat 2-1, 9712 TS Groningen, the Netherlands. E-mail: c.1.h.bockting@rug.nl 
Major depressive disorder (MDD) is a mood disorder with immense consequences for patients and society, and is associated with substantially reduced quality of life stretching out far beyond remission (Judd et al., 2000; Plaisier et al., 2010; ten Doesschate, Koeter, Bockting, \& Schene, 2010). The World Health Organization (WHO) estimated that by 2030, MDD will rank second in most disabling conditions worldwide (Mathers \& Loncar, 2006).

Part of MDDs disabling effect is due to its high risk of relapse that can rise to $80 \%$ in the absence of adequate treatment (Mueller \& Leon, 1999). Several risk factors for relapse have been identified, for example, early onset, number of previous episodes, residual symptoms, and episode severity (Burcusa \& Iacono, 2007; Judd et al., 1998; Kennedy \& Paykel, 2004; Paykel, Ramana, Cooper, \& Hayhurst, 1995). Potentially modifiable risk factors have been reported as well-including the impact of daily hassles and life events, specific coping styles, decentering, and dysfunctional beliefs (Beshai, Dobson, Bockting, \& Quigley, 2011; Bockting, Spinhoven, Koeter, Wouters, \& Schene, 2006; Burcusa \& Iacono, 2007; Fresco, Segal, Buis, \& Kennedy, 2007; Jarrett et al., 2012; ten Doesschate, Bockting, \& Schene, 2009).

Acute-phase cognitive therapy (A-CT) as well as preventive cognitive therapy (PCT) focus on presumed cognitive vulnerability factors of relapse, that is, underlying dysfunctional beliefs that are presumed to be latent in the remitted phase, but are easily activated by sad mood and thereby a trigger for depressive relapse. Cognitive therapy (CT) after remission, including mindfulness based cognitive therapy (MBCT), has shown to be an effective strategy in preventing relapse in depression (Guidi, Fava, Fava, \& Papakostas, 2011; Piet \& Hougaard, 2011; Vittengl, Clark, Dunn, \& Jarrett, 2007). Relative risk reduction (RR) of relapse when CT after remission and MBCT were compared to non-active controls has been documented (RR reduction CT: $36 \%$ in 232 patients; RR reduction MBCT: $34 \%$ in 408 patients) and was especially prominent in patients with three or more previous major depressive episodes (MDEs; Piet \& Hougaard, 2011; Vittengl et al., 2007). Enduring effects of CT that start after remission have been reported up to almost 6 years (Bockting, Spinhoven, Wouters, Koeter, \& Schene, 2009; Fava et al., 2004).

Since dysfunctional beliefs appeared to be dependent on mood, both the differential activation hypothesis of Teasdale (1988) and the mood state hypothesis of Miranda and Persons (1988) shifted the focus from unprimed dysfunctional beliefs toward moodlinked activation of these beliefs (i.e., cognitive reactivity [CR]) as a risk factor for relapse in depression. Several studies have found support for the prediction of relapse by cognitive reactivity after remission from MDD (233 patients; Kuyken et al., 2010; Segal, Gemar, \& Williams, 1999; Segal et al., 2006). Though, one recent study found no evidence for cognitive reactivity in patients remitted from MDD (Jarrett et al., 2012), whereas Lethbridge and Allen (2008) were unable to corroborate the predictive validity of cognitive reactivity (52 patients). Unfortunately methodological constraints limit the interpretation of these results. Only one of Segal's studies (Segal et al., 2006) randomized patients over treatment conditions. Moreover, interpretation of true mediation by change in cognitive reactivity is limited; both Segal et al. (1999) and Segal et al. (2006) were unable to examine pretreatment cognitive reactivity as they used currently depressed patient samples, and Kuyken et al. (2010) only measured post-treatment cognitive reactivity as well in their sample of remitted patients.
Besides reactivity of thought content, a dichotomous "black and white" thinking style (i.e., cognitive extremity [CE]) has also been related to relapse in depression (Beevers, Keitner, Ryan, \& Miller, 2003; Petersen et al., 2007; Teasdale et al., 2001). Cognitive extremity predicted relapse during continuation phase and was found to increase the risk of relapse by a factor of 2.5 (Teasdale et al., 2001). However, other studies failed to find cognitive extremity to predict relapse (Beevers et al., 2003; Jacobs et al., 2010). Although we are unaware of any studies that investigated mood-linked change in cognitive extremity (i.e., cognitive extremity reactivity $[\mathrm{CER}])$, mood-linked changes in explanatory flexibility (i.e., the flexibility or rigidity of assigning causes to certain events) have been examined (Fresco, Heimberg, Abramowitz, \& Bertram, 2006; Fresco, Rytwinski, \& Craighead, 2007). Following mood-provocation, explanatory flexibility decreased in participants with a history of MDD (Fresco et al., 2006).

In addition, changes in mood itself following mood provocation (i.e., mood reactivity $[\mathrm{MR}]$ ) also appear to be related to relapse in depression (Ehring, Fischer, Schnülle, Bösterling, \& TuschenCaffier, 2008; Ehring, Tuschen-Caffier, Schnülle, Fischer, \& Gross, 2010; Lethbridge \& Allen, 2008). This implies that the inability to effectively regulate affect during emotional or stressful events could signal the return of depressive symptomatology. Remitted patients who failed to show an adequate reduction in self-rated happiness after a sad mood provocation were at increased risk of relapse over 12 months (Lethbridge \& Allen, 2008). This so called emotion context insensitivity (ECI) has been associated with poor psychosocial functioning and depression status later in time (Peeters, Berkhof, Rottenberg, \& Nicolson, 2010; Rottenberg, Kasch, Gross, \& Gotlib, 2002). Mood reactivity appears to reflect underlying stress susceptibility (Britton, Shahar, Szepsenwol, \& Jacobs, 2012), in that mood reactivity to stressful events appears to be related to the onset of depressive symptoms (Cohen, Gunthert, Butler, O’Neill, \& Tolpin, 2005).

Few studies have focused on the underlying mechanism of preventive CT after remission from MDD, and those that did focused on MBCT. Two studies had inconsistent results in examining rumination as a mediator of the effect of MBCT on depressive symptoms (Bieling et al., 2012; Shahar, Britton, Sbarra, Figueredo, \& Bootzin, 2010). To date, only one study directly tested mediation by cognitive reactivity on the preventive effect of CT on relapse (Kuyken et al., 2010), which was unable to demonstrate that MBCT exerted its effects on relapse through posttreatment cognitive reactivity. One limitation of this study is the absence of baseline cognitive reactivity, limiting the interpretation of possible mediating effects. Finally, a recent study demonstrated partial mediation on the effect of MBCT on depressive symptoms by emotional reactivity following the Trier Social Stress Task (Britton et al., 2012). The current study is the first to examine whether changes in cognitive reactivity and mood reactivity mediate the preventive effect of PCT on relapse.

The present study is a secondary analysis of a randomized trial that investigated the effectiveness of PCT in preventing relapse in MDD up to 5.5 years after remission (Bockting et al., 2005, 2009). This study aims to examine whether (a) unprimed (latent) baseline cognitive vulnerability is predictive for relapse over 5.5 years; (b) cognitive reactivity, cognitive extremity reactivity, and mood reactivity are predictive for relapse over 5.5 years; (c) this reactivity is modifiable by brief PCT; and (d) changes in reactivity 
following treatment mediate the effect of PCT on reducing risk of relapse.

\section{Method}

\section{Participants}

In order to participate in the current study, patients had to have (a) experienced two or more MDEs in the previous 5 years; (b) current remission of the last MDE for at least 10 weeks but no longer than 2 years, both defined according to the Diagnostic and Statistical Manual of Mental Disorders (4th ed.; DSM-IV; American Psychological Association, 1994) and assessed with the Structured Clinical Interview for DSM-IV Axis I Disorders (SCID-I; Spitzer, Williams, Gibbon, \& First, 1990) administered by trained interviewers; and (c) a current score of $<10$ on the Hamilton Depression Rating Scale $\left(\mathrm{HDRS}_{17}\right.$; Hamilton, 1960). Exclusion criteria were as follows: current mania, hypomania, a history of bipolar illness, any psychotic disorder (current and previous), organic brain damage, current alcohol or drug abuse, predominant anxiety disorder, recent electroconvulsive therapy (ECT), recent cognitive treatment or CT at the start of the study, or current psychotherapy with a frequency of more than twice a month. The protocol was approved by the institutional ethics review committees. See Bockting et al. $(2005,2009)$ for more details.

\section{Design}

Participants were screened for eligibility using the telephone version of the SCID-I. Current and past depressive episodes were checked at baseline and at five follow-up assessments $(3,12,24$, 36, and 66 months). Participants who met the inclusion criteria were randomly allocated to (a) treatment as usual (TAU) or (b) TAU + PCT. Randomization was performed using randomly permuted blocks in strata of study location and type of aftercare (general practitioner/psychiatric center/no aftercare).

\section{Treatment}

Preventive cognitive therapy. Participants in the experimental condition received eight weekly 2-hr sessions of PCT in groups of 7-12 patients. PCT is based on Beck, Rush, Shaw, and Emery's (1979) acute-phase CT (Bockting et al., 2005) and focused mainly on identification of negative thoughts and dysfunctional attitudes, and subsequent challenging of these attitudes using different cognitive techniques including Socratic dialogue (Bockting, 2009). Moreover, participants were encouraged to practice with alternative attitudes. They were also asked to keep a diary of positive experiences in order to enhance specific memories of positive experiences. In the final three sessions, relapse prevention strategies were formulated individually. Nine specifically trained psychologists, all fully trained as cognitive behavior therapists (minimum 5 years of training), delivered the intervention. All intervention group sessions were audiotaped to enable treatment integrity evaluation, using a checklist of all particular interventions. Treatment adherence was monitored between sessions, and any adherence or competence issues were resolved with the therapist prior to the subsequent session. This occurred only once, following an overlooked homework assignment.
Treatment as usual (TAU). TAU involved "naturalistic" care, that is, standard treatment (including primary care, specialty care and no treatment). There was no restriction on the use of antidepressant medication (ADM) during the period from entry through follow-up; however, actual ADM use was monitored.

\section{Measures}

Visual Analogue Scale (VAS). Patients rated their current mood on a Visual Analogue Scale (VAS) measuring $100 \mathrm{~mm}$. The left end of the scale was labeled "happy," and the right end was labeled "sad."

Dysfunctional Attitude Scale (DAS). The 40-item Dutch adaptation of the DAS (Douma, 1991; Weissman, 1979) was used to examine levels of dysfunctional beliefs (e.g., rigid schemes or attitudes). Patients rated their agreement with the 40-items on a 7-point scale that ranged from totally agree to totally disagree. Two versions of the DAS (A and B) were used in the current study, and have previously been shown to have good reliability ( $\alpha=.86$ and .87, respectively; Dozois, Covin, \& Brinker, 2003). In the current study, both demonstrated excellent internal consistency $(\alpha=.94)$ and were highly correlated $(r=.85)$.

Mood provocation procedure. Patients completed a mood provocation procedure as described by Segal et al. (1999, 2006) following inclusion in the study. Patients listened to a piece of music by Prokofiev called "Russia under the Mongolian Yoke" from the movie Alexander Nevsky. The orchestral introduction of this musical piece was played at half speed on a tape recorder and patients were instructed to recall a time in their life when they felt sad. Patients first completed a VAS rating of sad mood and the DAS-A after which Prokofiev's piece was played for $10 \mathrm{~min}$. Immediately thereafter, patients again completed a VAS rating and the DAS-B. An average mood change of at least $10 \%$ on the VAS is considered to indicate successful mood provocation (Martin, 1990; Segal et al., 2006). This procedure was repeated for all patients 3 months later.

Relapse/recurrence. Relapse has been defined as the reemergence of the index episode of depression within 6 months after initial remission, whereas a recurrence is proposed to represent a new episode occurring after 12 months of recovery (Hollon, Stewart, \& Strunk, 2006). Since we included patients in remission for at least 10 weeks but no longer than 2 years, we chose to adopt a conservative approach. Therefore, and for sake of readability, relapse refers to the return of a depressive episode. The main outcome measure, time to relapse, was assessed with the SCID-I. At the five follow-up assessments, current and MDEs preceding the follow-up point were checked for all patients. To keep the assessors blind to treatment condition, we instructed participants not to reveal this information to the interviewers. Kappa (к) for interrater agreement on relapse between the interviewers and an independent psychiatrist, assessed over the follow-up period, ranged from .94 to .96 , indicating excellent agreement.

Construct operationalization. Endorsement of dysfunctional beliefs (unprimed) was calculated by the sum score of all items on the baseline DAS. Extremity of these beliefs was the total number of totally agree and totally disagree responses on the DAS. Following mood provocation, cognitive reactivity was the change in DAS scores, cognitive extremity reactivity was the change in extreme responses, and mood reactivity was the change in score on 
the VAS. On an exploratory basis, we examined the course of reactivity over time by subtracting pretreatment from posttreatment reactivity scores.

Statistical analyses. To examine the prediction of relapse by baseline unprimed dysfunctional beliefs (DAS-A) and cognitive extremity on the DAS-A (CE), we used survival analysis (i.e., Cox regression) with time to first relapse as main outcome. All analyses were done on an intention to treat (ITT; including all randomized patients) and completers (patients attending $\geq 5$ PCT sessions) basis. Patients who dropped-out during follow-up or who did not relapse within 5.5 years were treated as censored in ITT and completers analyses, meaning that their information was usefully taken into account by the Cox model.

These analyses were then repeated separately with cognitive-, cognitive extremity- and mood-reactivity as predictors of relapse. We analyzed baseline, post-treatment and, on an exploratory basis, the course of reactivity measurements following PCT (posttreatmentpretreatment) in order to assess the mediating effect of PCT. In line with Segal et al. (2006), we used the saved standardized residuals (ZresDAS, ZresVAS, ZresExtremeResponses) from the linear regression of pre-induction on post-induction scores as the independent variable in the survival analysis to reduce the impact of baseline variability.

To assess whether PCT moderated the relation between the predictors and relapse, we examined Condition $\times$ Predictor interactions and Condition $\times$ Predictor $\times$ Previous MDEs interactions for all predictors, since in a previous study the number of previous MDEs was a moderator in the prediction of relapse (Bockting et al., 2005, 2009). If PCT was a significant moderator, then the survival analysis would have to be restricted to the control group only, otherwise the analysis could be performed on the complete sample. All models were checked for confounding effects of residual depressive symptoms $\left(\mathrm{HDRS}_{17}\right)$ and use of ADM.

Finally, we were interested in the mediating effect of changes in cognitive-, cognitive extremity-, and mood-reactivity on the effect of PCT on relapse in 5.5 years. Since the effectiveness of PCT depended on the number of previous MDEs with the cutoff point at four previous episodes (Bockting et al., 2005, 2009), its impact was examined in a subset of patients with four or more previous MDEs which included more than half the sample. The effect of PCT on the course of cognitive-, cognitive extremity-, and moodreactivity was determined in three separate linear regression models in which we predicted $Z_{\text {res }}$ post with treatment condition and Zres $_{\text {pre }}$ as independent variables. The amount of mediation of the effect of PCT on relapse by the course of cognitive-, cognitive extremity-, and mood-reactivity was defined as the change in the magnitude of the effect of PCT on relapse when including the pretreatment to post-treatment change in the Cox model as independent variables. The amount of mediation was scaled as the relative change in the beta coefficient (log hazard ratio) for PCT, and was expressed as a percentage. In randomized trials this is often called the proportion of treatment effect explained (Freedman, Graubard, \& Schatzkin, 1992). More than a 5\% change in a regression coefficient when a covariate is added is generally considered substantial (Maldonado \& Greenland, 1993).

As a previous study only used post-treatment cognitive reactivity as a mediator (Kuyken et al., 2010), we replicated these analyses with a Cox model including PCT, post-treatment cognitive reactivity, and PCT $\times$ Post-Treatment Cognitive Reactivity interactions only, with number of previous MDEs, gender, posttreatment $\mathrm{HDRS}_{17}$, and mood reactivity as covariates (Kuyken et al., 2010). A significant interaction $(\mathrm{PCT} \times \mathrm{CR})$ and main effect of cognitive reactivity would have indicated a mediating effect of cognitive reactivity (Kraemer, Wilson, Fairburn, \& Agras, 2002).

\section{Results}

\section{Patient Flow}

In total, 187 formerly depressed patients were randomized. For the ITT analyses we excluded 15 patients (dropouts) in total-nine from TAU + PCT because they did not attend any session and six from TAU because they dropped out from the study immediately. The resulting 172 patients were analyzed on an ITT basis. Dropouts were slightly younger than the ITT group, $t(170)=-2.25$, $p=.03$, but did not differ on any of the other characteristics. For the Completers group $(n=165)$, we excluded an additional seven patients who attended less than five PCT sessions. NonCompleters were younger, $t(170)=-2.85, p=.005$, and had a lower score on the DAS, $t(170)=-2.01, p=.048$, than Completers. A previous study on this sample demonstrated that PCT, when added to TAU, was effective in reducing cumulative relapse risk over 5.5 years, Wald $\chi^{2}(1, N=172)=8.80, p=.003$, hazard ratio $=0.56$. With the indicating cutoff being four previous MDEs, dichotomized number of previous MDEs (fewer than four vs. four or more) resulted in a significant interaction between treatment condition and number of previous MDEs, Wald $\chi^{2}(1, N=172)=$ $7.76, p=.02$, hazard ratio $=0.379$. The median survival time in patients with four or more previous MDEs was 713 weeks (TAU + PCT) compared to 205 weeks (TAU). PCT reduced cumulative relapse over 5.5 years from $95 \%$ (TAU) to $75 \%$ (TAU + PCT). The results were closely similar within the Completers group (Bockting et al., 2009).

\section{Patient Characteristics}

Demographic and clinical characteristics of the ITT group are summarized in Table 1. Patient groups did not differ on any of the demographic variables. Initial baseline DAS-A scores differed between conditions, $F(1,170)=4.023, p=.046$. The same differences were observed for post-treatment DAS-A and DAS-B scores: DAS-A, $F(1,170)=3.993, p=.047$; DAS-B, $F(1,170)=$ $4.477, p=.036$. However, we controlled for initial DAS differences by using standardized residual DAS scores in our analyses. No baseline differences in CR, CER, or MR were revealed and neither did the level of CR, MR, or CER differ between patients who were on ADM versus patients who were not.

\section{Mood Provocation}

Mood provocation at both baseline and post-treatment was successful (average change was $>10 \%$; Martin, 1990), and increased sad mood according to the VAS with, respectively, 22.9 $\mathrm{mm}$ and $20.8 \mathrm{~mm}$ in the TAU and $21.3 \mathrm{~mm}$ and $17.2 \mathrm{~mm}$ in the $\mathrm{TAU}+\mathrm{PCT}$ group (difference $n s$ between groups) 
Table 1

Demographic and Clinical Characteristics $(\mathrm{N}=172)$

\begin{tabular}{|c|c|c|}
\hline Variable & $\begin{array}{c}\text { TAU } \\
(n=84)\end{array}$ & $\begin{array}{c}\text { TAU }+ \text { PCT } \\
(n=88)\end{array}$ \\
\hline \multicolumn{3}{|l|}{ Characteristic $^{\mathrm{a}}$} \\
\hline Female \% $(n)$ & $73.8(62)$ & $72.7(64)$ \\
\hline Age & $43.4(9.8)$ & $45.9(9.1)$ \\
\hline $\begin{array}{l}\text { Previous episodes (median; IQR, } \\
\text { No. }^{\text {b) }}\end{array}$ & $3.0 ; 3.8,2.8$ & $4.0 ; 3.8,2.9$ \\
\hline Age of first onset & $28.1(12.5)$ & $28.8(12.6)$ \\
\hline antidepressants \% $(n)$ & $50.0(42)$ & $52.2(46)$ \\
\hline Cumulative relapse over 5.5 years $^{\mathrm{c}} \%$ & $95(79)$ & $75(82)$ \\
\hline Median survival time over 5.5 years $^{\mathrm{d}}$ & $205.0(502.0)$ & $713.0(502.0)$ \\
\hline \multicolumn{3}{|l|}{ Pretreatment } \\
\hline $\mathrm{HDRS}_{17}$ & 3.7 (2.9) & $3.8(2.8)$ \\
\hline DAS-A & 129.4( & $119.2(2$ \\
\hline DAS & 22.4( & 114.4( \\
\hline $\mathrm{CE}$ & $7.1(9.0)$ & $6.9(6.6)$ \\
\hline $\mathrm{CR}_{\mathrm{DAS}}$ & $-7.0(14.8)$ & $-4.8(18.5)$ \\
\hline $\mathrm{CER}_{\mathrm{DAS}}$ & $-1.4(5.2)$ & $-1.1(4.4)$ \\
\hline $\mathrm{MR}_{\mathrm{VAS}}$ & $2.3(2.4)$ & $2.1(2.3)$ \\
\hline \multicolumn{3}{|l|}{ ost-treatment } \\
\hline $\mathrm{HDRS}_{17}$ & $6.5(6.1)^{* * *}$ & $4.0(4.4)^{* * *}$ \\
\hline DAS-A & $122.4(32.2)^{*}$ & $113.4(26.8)^{*}$ \\
\hline DAS-B & $118.6(29.8)^{*}$ & $109.8(25.0)^{*}$ \\
\hline $\mathrm{CR}_{\mathrm{DAS}}$ & $-3.8(16.2)$ & $-3.6(16.2)$ \\
\hline $\mathrm{CER}_{\mathrm{DAS}}$ & $-1.4(4.3)$ & $-0.9(4.8)$ \\
\hline $\mathrm{MR}_{\mathrm{VAS}}$ & $2.1(2.1)$ & $1.7(1.9)$ \\
\hline \multicolumn{3}{|c|}{$\begin{array}{l}\text { Note. TAU = treatment as usual; PCT = preventive cognitive therapy; IQR } \\
=\text { interquartile range; } \mathrm{HDRS}_{17}=17 \text {-item Hamilton Depression Rating Scale; } \\
\text { DAS-A = Dysfunctional Attitude Scale Form A; DAS-B = Dysfunctional } \\
\text { Attitude Scale Form B; CE = cognitive extremity on the baseline DAS; CR = } \\
\text { cognitive reactivity (post-pre induction DAS); CER = cognitive extremity } \\
\text { responding reactivity (post-pre induction extremity DAS); MR = mood } \\
\text { reactivity (post-pre induction Visual Analogue Scale [VAS]). } \\
\text { a All values represent } M(S D) \text { unless stated otherwise. }{ }^{\mathrm{b}} \text { Average number } \\
\text { of dichotomized previous episodes (two or three and more). }{ }^{\mathrm{c}} \text { Cumulative } \\
\text { relapse over } 66 \text { months in patients with four or more and, in parentheses, } \\
\text { with less than four previous major depressive episodes (MDEs). }{ }^{\mathrm{d}} \text { Me- } \\
\text { dian survival time in weeks for patients with four or more previous and, in } \\
\text { parentheses, with less than four previous MDEs. } \\
{ }^{*} p<.05 .{ }^{* * *} p<.01 \text {. }\end{array}$} \\
\hline
\end{tabular}

\section{Interaction With Condition and Number of Previous MDEs}

For each predictor, separate Cox models were fitted including the three-way interaction (Predictor $\times$ Condition $\times$ Previous MDEs) and, second, including the two-way interaction (Predictor $\times$ Condition). Since none of the interaction terms were significant and neither depressive residual symptoms, use of $\mathrm{ADM}$, nor condition confounded the predictor of interest, interaction terms were subsequently dropped from the model, and Cox regression was fitted on the ITT sample $(N=172)$ for each predictor. Results on completers were not different from ITT and were therefore omitted from the results (in the online supplemental materials, see Tables I and II for interaction coefficients, and see Table III for completers).

\section{Baseline Risk of Relapse: Unprimed Dysfunctional Beliefs and Cognitive Extremity}

Cox regression revealed that dysfunctional beliefs but not cognitive extremity were predictive of time to relapse in 5.5 years:
DAS-A, Wald $\chi^{2}(1, N=172)=12.294, p \leq .001$, hazard ratio $=$ 1.01; CE, Wald $\chi^{2}(1, N=172)=1.663, p=.197$, hazard ratio $=$ 0.99 (see Table 2). Increases in DAS-A by one unit increased prospective risk of relapse by $1 \%$, and DAS-A remained a significant predictor when the number of previous MDEs and depressive symptoms were added to the model. Moreover, with cognitive reactivity already in the model, the DAS-A also remained a significant predictor of time to relapse.

\section{Prediction of 5.5-Year Relapse by Cognitive Reactivity and Cognitive Extremity Reactivity}

Including all 172 patients in the Cox regression, neither baseline cognitive reactivity nor cognitive extremity reactivity predicted time to relapse within 5.5 years: $\mathrm{CR}$, Wald $\chi^{2}(1, N=172)=$ $1.143, p=.285$, hazard ratio $=0.90 ; \operatorname{CER}$, Wald $\chi^{2}(1, N=$ $172)=0.751, p=.386$, hazard ratio $=1.08$. Moreover, baseline residuals for the DAS change score did not differ significantly between patients who relapsed within 5.5 years and patients who did not, $F(1,170)=2.292, p=.132$.

Table 2

Predictors of Time to Relapse Within 5.5 Years (ITT, N = 172)

\begin{tabular}{|c|c|}
\hline Variable & Predictor $\left(\beta_{1}\right)$ \\
\hline \multicolumn{2}{|l|}{ Pretreatment } \\
\hline \multicolumn{2}{|l|}{$\mathrm{DAS}_{\text {Form A }}$} \\
\hline$\beta$ & 0.008 \\
\hline$S E(\beta)$ & 0.002 \\
\hline$p$ & 0.000 \\
\hline \multicolumn{2}{|l|}{$\mathrm{CE}$} \\
\hline$\beta$ & -0.015 \\
\hline$S E(\beta)$ & 0.012 \\
\hline$p$ & 0.197 \\
\hline \multicolumn{2}{|l|}{$\mathrm{CR}_{\mathrm{DAS}}$} \\
\hline$\beta$ & -0.101 \\
\hline$S E(\beta)$ & 0.094 \\
\hline$p$ & 0.285 \\
\hline \multicolumn{2}{|l|}{$\mathrm{CER}_{\text {DAS }}$} \\
\hline$\beta$ & 0.073 \\
\hline$S E(\beta)$ & 0.084 \\
\hline$p$ & 0.386 \\
\hline \multicolumn{2}{|l|}{$\mathrm{MR}_{\mathrm{VAS}}$} \\
\hline$\beta$ & 0.021 \\
\hline$S E(\beta)$ & 0.084 \\
\hline$p$ & 0.807 \\
\hline \multicolumn{2}{|c|}{ Post-treatment } \\
\hline \multicolumn{2}{|l|}{$\mathrm{CR}_{\mathrm{DAS}}$} \\
\hline$\beta$ & 0.134 \\
\hline$S E(\beta)$ & 0.092 \\
\hline$p$ & 0.147 \\
\hline \multicolumn{2}{|l|}{$\mathrm{CER}_{\mathrm{DAS}}$} \\
\hline$\beta$ & 0.015 \\
\hline$S E(\beta)$ & 0.083 \\
\hline$p$ & 0.854 \\
\hline \multicolumn{2}{|l|}{$\mathrm{MR}_{\mathrm{VAS}}$} \\
\hline$\beta$ & 0.241 \\
\hline$S E(\beta)$ & 0.084 \\
\hline$p$ & 0.004 \\
\hline
\end{tabular}

Note. All predictors remain significant after applying a Bonferroni correction of $\alpha / 8=.006$. ITT $=$ intention to treat; $\mathrm{DAS}_{\mathrm{Form} \mathrm{A}}=$ Dysfunctional Attitude Scale Form A; CE = cognitive extremity on the DAS before mood provocation; $\mathrm{CR}_{\mathrm{DAS}}=$ cognitive reactivity on the DAS; $\mathrm{CER}_{\mathrm{DAS}}=$ changes in cognitive extremity on the DAS following mood provocation; $\mathrm{MR}_{\mathrm{VAS}}=$ mood reactivity on the Visual Analogue Scale 
Until now, only post-treatment cognitive reactivity had been examined (Kuyken et al., 2010; Segal et al., 1999, 2006). We therefore repeated previous analyses for post-treatment cognitive reactivity and cognitive extremity reactivity. Still, both were not predictive for time to relapse: CR, Wald $\chi^{2}(1, N=172)=2.103$, $p=.147$, hazard ratio $=1.14$; CER, Wald $\chi^{2}(1, N=172)=$ $0.034, p=.854$, hazard ratio $=1.02$, and the residuals of the DAS change scores did not differ between patients who relapsed within 5.5 years and patients who did not, $F(1,170)=0.088, p=.767$.

Although the mood provocation was successful overall, sadness on the VAS did not increase with $\geq 10 \%$ in all patients. We therefore repeated the cognitive reactivity analyses while selecting patients on their level of increase in sadness on the VAS. The results did not change when we selected patients with an increase in sadness on the pretreatment VAS of at least $10 \%(n=121$, $p=.335)$, and similarly of at least $20 \%(n=95, p=.709), 30 \%$ $(n=62, p=.825), 40 \%(n=36, p=.975)$, and $50 \%(n=20$, $p=.781$ ), respectively. Similar results were obtained for posttreatment cognitive reactivity, although we could only select patients with a mood change up to $40 \%$, since the number of events (i.e., relapses) in the survival analysis was below 10 for patients with a mood change of $50 \%$ or more ( $n=9 ; 4.8 \%$ of the sample).

\section{Prediction of 5.5-Year Relapse by Mood Reactivity}

Cox regression for change in negative mood following mood provocation revealed that baseline mood reactivity did not predict time to relapse within 5.5 years: MR, Wald $\chi^{2}(1, N=172)=$ $0.059, p=.807$, hazard ratio $=1.02$. Furthermore, no difference in relapse emerged between patients unresponsive to the mood provocation (i.e., no mood response or positive mood increase; $n=26 ; 77 \%$ relapse) and patients experiencing a negative mood $(n=109 ; 79 \%$ relapse $)(p=.455$, Fisher exact test $)$.

At post-treatment, however, higher mood reactivity was predictive of time to relapse, Wald $\chi^{2}(1, N=172)=8.285, p=.004$, hazard ratio $=1.27$.

\section{Effect of PCT on Cognitive Reactivity and Mood Reactivity}

In order to examine mediation by change in cognitive reactivity, cognitive extremity reactivity, and mood reactivity on the effect of PCT on relapse, we first examined whether the course (change over 3 months) of reactivity measurements was predictive of relapse. Patients who became increasingly mood reactive and cognitive reactive (but not cognitive extremity reactive) were at increased risk of relapse: $\mathrm{CR}$, Wald $\chi^{2}(1, N=172)=6.765, p=$ .009 , hazard ratio $=1.25 ; \mathrm{MR}$, Wald $\chi^{2}(1, N=172)=6.853, p=$ .009 , hazard ratio $=1.25$; CER, Wald $\chi^{2}(1, N=172)=0.348$, $p=.555$, hazard ratio $=0.96$. However, after we selected patients with four or more previous MDEs (for mediation purposes), the course of reactivity measurements was no longer predictive of time to relapse.

Second, PCT was not related to changes in cognitive reactivity, cognitive extremity reactivity, or mood reactivity over time as putative mediators on the effect of PCT on relapse (see Figure 1), although PCT did prolong time to relapse in 5.5 years.

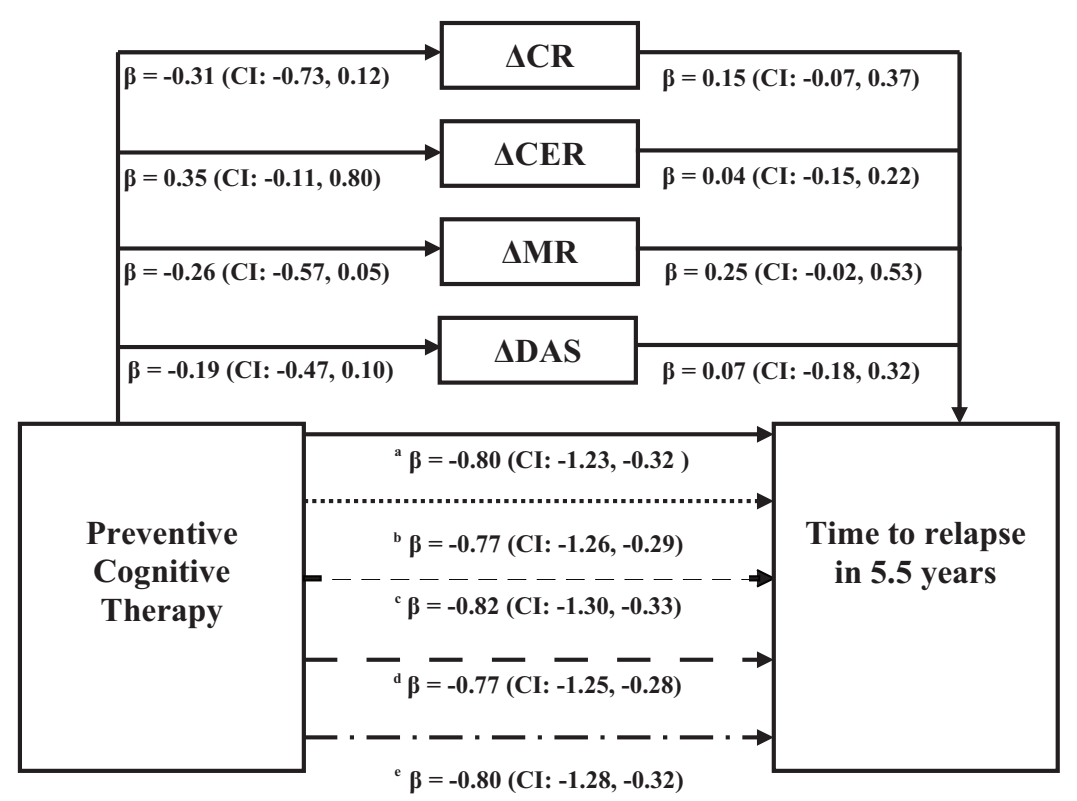

Figure 1. Four multiple regression mediation models in patients with four or more previous major depressive episodes. Change in cognitive reactivity (CR), cognitive extremity responding reactivity (CER), mood reactivity (MR), and Dysfunctional Attitude Scale (DAS) were entered separately. ${ }^{a}$ Represents the direct effect. ${ }^{\mathrm{b}}$ Represents the $\beta$ after $\Delta \mathrm{CR}$ was added to the model (effects of preventive cognitive therapy [PCT] mediated by $\Delta \mathrm{CR}=3.1 \%$ ). ${ }^{\mathrm{c}}$ Represents the $\beta$ after $\Delta$ CER was added to the model (effects of PCT mediated by $\Delta$ CER $=-2.3 \%$ ). ${ }^{\mathrm{d}}$ Represents the $\beta$ after $\Delta \mathrm{MR}$ was added to the model (effects of PCT mediated by $\Delta \mathrm{MR}=3.9 \%$ ). ${ }^{\mathrm{e}}$ Represents the $\beta$ after $\Delta \mathrm{DAS}$ was added to the model (effects of PCT mediated by $\triangle \mathrm{DAS}=-0.3 \%$ ). 
Relative changes in beta's when adding $\triangle \mathrm{CR}, \triangle \mathrm{CER}$, and $\triangle \mathrm{MR}$ separately to the model with PCT alone were small and ranged between 3.1 and $3.9 \%$, indicating that the relation between PCT and time to relapse was not mediated by change in cognitive reactivity, cognitive extremity reactivity, or mood reactivity. Additionally, we examined whether change in unprimed (latent) dysfunctional beliefs possibly mediated the preventive effect of PCT. Mediation by unprimed dysfunctional beliefs was also not supported by our analyses (change in beta PCT $=-0.3 \%$ ). Similar results were obtained for completers. Finally, we also replicated previous mediation analysis with post-treatment cognitive reactivity only (Kuyken et al., 2010). Again, no indications for mediation were found (see Table IV in the online supplemental materials).

\section{Discussion}

To our knowledge, this was the first study that prospectively examined the combination of primed and unprimed cognitive and emotional vulnerability as risk factors for relapse over 5.5 years. Moreover, we are unaware of any studies that examined whether changes in cognitive and emotional vulnerability mediated the effect of PCT in preventing relapse over 5.5 years.

Our findings show that mood reactivity instead of cognitive reactivity and cognitive extremity reactivity predicted relapse over 5.5 years. Further, unprimed dysfunctional beliefs predicted relapse directly, whereas unprimed cognitive extremity did not. We found no indication that cognitive reactivity mediated the effect of PCT, which is in line with findings of Kuyken et al. (2010) using MBCT. Finally, neither cognitive extremity reactivity, nor mood reactivity or unprimed dysfunctional beliefs mediated the preventive effect of PCT on relapse. Explorative analyses revealed that the course of both cognitive reactivity and mood reactivity (i.e., increases in reactivity) was predictive of time to relapse.

Our finding that mood reactivity predicted relapse over 5.5 years supports findings of several other studies, although their follow up was restricted to a maximum of 12 months (Lethbridge \& Allen, 2008; Rucci et al., 2011). Especially an increase in negative mood (i.e., self-rated sadness) was predictive of relapse. Lethbridge and Allen (2008) found that the absence of positive mood decrease following mood provocation was predictive of 12-month relapse. Recent studies on mood reactivity in depression highlight the role of daily stress as a provoking factor for mood reactivity and relapse in depressive symptomatology and highlight the role of measuring mood reactivity in daily life (Bockting et al., 2006; Britton et al., 2012; Bylsma, Taylor-Clift, \& Rottenberg, 2011; Peeters et al., 2010; ten Doesschate et al., 2009). We speculate that patients who are highly reactive when confronted with a sad or very stressful event might be more susceptible to experiencing negative affect, in turn making them more vulnerable for relapse. This is in line with previous studies that reported evidence for the role of daily hassles and for the ability of lower severity life-events to predict relapse and recurrence (Bockting et al., 2006; Cohen et al., 2005; Monroe \& Harkness, 2005; Stroud, Davila, Hammen, \& Vrshek-Schallhorn, 2011). Future studies should attempt to unravel the link between mood reactivity and daily stress further.

The finding that cognitive reactivity does not play a role as risk factor for relapse is in line with a previous study that was unable to demonstrate that cognitive reactivity predicted relapse over 12 months in a community sample (Lethbridge \& Allen, 2008). Nev- ertheless, there is also supportive evidence for cognitive reactivity as a vulnerability factor for relapse (Kuyken et al., 2010; Segal et al., 1999, 2006). Explorative analyses revealed that the course of cognitive reactivity over time was also predictive of relapse (i.e., patients with increases in cognitive reactivity over time were more at risk). Cognitive reactivity might have to be assessed repeatedly to detect its impact on relapse. Since no other study reported on the course of cognitive reactivity, no firm conclusions can be drawn and replication is required. Moreover, since the current study and many previous studies found support for the prediction of relapse by unprimed dysfunctional beliefs directly (Jarrett et al., 2012; Rush, Weissenburger, \& Eaves, 1986; Simons, Murphy, Levine, \& Wetzel, 1986; Thase et al., 1992), the practical question is raised why one would use a complicated repeated mood provocation instead of a single questionnaire (the DAS) in order to determine vulnerability for relapse.

Our findings question the assumption that dysfunctional beliefs have to be activated in the remitted phase to act as a vulnerability factor (Miranda \& Persons, 1988; Teasdale, 1988). Although we found significant average change in dysfunctional beliefs following both mood provocations (pretreatment: 5.9 points decrease, post-treatment: 3.7 points decrease; $n s$ between conditions), in line with previous studies (Kuyken et al., 2010; Lethbridge \& Allen, 2008; Miranda, Gross, Persons, \& Hahn, 1998; Segal et al., 1999; Van der Does, 2002, 2005), other studies did not (Jarrett et al., 2012; Miranda \& Persons, 1988). Moreover, differential dysfunctional belief activation between remitted patients and never depressed controls remains controversial (Brosse \& Craighead, 1999; Dykman, 1997; Fresco et al., 2006; Miranda et al., 1998; Otto et al., 2007; Silverman, Silverman, \& Eardley, 1984).

Finally, we found no indications for a modifying effect of PCT on changes in dysfunctional beliefs (i.e., cognitive reactivity and extremity reactivity) or mood reactivity, and moreover, no evidence that changes in these reactivity measures mediated the effect of PCT on reducing the risk of relapse. Yet, the preventive CT used in this study was found to be effective in increasing survival time and reducing cumulative relapse risk up to 5.5 years (Bockting et al., 2005, 2009). Studies on potential mediators of CT after remission have so far provided mixed results (Bieling et al., 2012; Britton et al., 2012; Kuyken et al., 2010; Shahar et al., 2010). Unfortunately, like the before mentioned studies, we were also unable to pinpoint a mediator of the effect of CT after remission. It is therefore currently still unknown how CT after remission exerts its effects on relapse and recurrence.

The current study has several limitations. Differences in cognitive reactivity between the current study and previous studies could relate to differences in patient samples. Our sample consisted of highly recurrent depressed patients currently in remission ( $M=6.5$ previous MDEs, compared to $M \mathrm{~s}=4.8,1.9$, and 6.1 in Segal et al., 1999; Lethbridge \& Allen, 2008; and Kuyken et al., 2010, respectively). Particularly the sample of Segal et al. (2006) differed in number of previous MDEs (average of dichotomized 1 vs. 2 or more previous MDEs was 1.69 , compared to 2.81 in our sample). For highly recurrent patients, vulnerability factors might be different than for patients with fewer episodes (Bockting et al., 2006; Daley, Hammen, \& Rao, 2000; Lewinsohn, Allen, Seeley, \& Gotlib, 1999). Finally, the question remains whether laboratoryinduced sadness is generalizable to elicited sad mood in daily life, 
and what this contributes to our knowledge about vulnerability factors for relapse.

In sum, the current study indicated that mood reactivity after mood provocation predicted relapse in depression while cognitive reactivity did not. Since unprimed dysfunctional beliefs did predict time to relapse directly, the clinical usefulness of a repeated mood provocation over a single DAS questionnaire is questioned. Future studies in this area should focus not only on the experience of daily sad mood and on the role of stress as a provoking factor of mood reactivity, but also on the meaning of the course of cognitive reactivity (i.e., changes in reactivity over time).

\section{References}

American Psychological Association. (1994). Diagnostic and statistical manual of mental disorders (4th ed.). Washington, DC: Author.

Beck, A. T., Rush, A. J., Shaw, B. F., \& Emery, G. (1979). Cognitive therapy of depression. New York, NY: Guilford Press.

Beevers, C. G., Keitner, G. I., Ryan, C. E., \& Miller, I. W. (2003). Cognitive predictors of symptom return following depression treatment. Journal of Abnormal Psychology, 112, 488-496. doi:10.1037/0021843X.112.3.488

Beshai, S., Dobson, K. S., Bockting, C. L. H., \& Quigley, L. (2011). Relapse and recurrence prevention in depression: Current research and future prospects. Clinical Psychology Review, 31, 1349-1360. doi: 10.1016/j.cpr.2011.09.003

Bieling, P. J., Hawley, L. L., Bloch, R. T., Corcoran, K. M., Levitan, R. D., Young, L. T., . . Segal, Z. V. (2012). Treatment-specific changes in decentering following mindfulness-based cognitive therapy versus antidepressant medication or placebo for prevention of depressive relapse. Journal of Consulting and Clinical Psychology, 80, 365-372. doi: $10.1037 / \mathrm{a} 0027483$

Bockting, C. L. H. (2009). Preventieve cognitieve training bij terugkerende depressie [Preventive cognitive therapy in recurrent depression]. Houten, the Netherlands: Bohn Stafleu van Loghum.

Bockting, C. L. H., Schene, A. H., Spinhoven, P., Koeter, M. W. J., Wouters, L. F., Huyser, J., \& Kamphuis, J. H. (2005). Preventing relapse/recurrence in recurrent depression with cognitive therapy: A randomized controlled trial. Journal of Consulting and Clinical Psychology, 73, 647-657. doi:10.1037/0022-006X.73.4.647

Bockting, C. L. H., Spinhoven, P., Koeter, M. W. J., Wouters, L. F., \& Schene, A. H. (2006). Prediction of recurrence in recurrent depression and the influence of consecutive episodes on vulnerability for depression: A 2-year prospective study. Journal of Clinical Psychiatry, 67, 747-755. doi:10.4088/JCP.v67n0508

Bockting, C. L. H., Spinhoven, P., Wouters, L. F., Koeter, M. W. J., \& Schene, A. H. (2009). Long-term effects of preventive cognitive therapy in recurrent depression: A 5.5-year follow-up study. Journal of Clinical Psychiatry, 70, 1621-1628. doi:10.4088/JCP.08m04784blu

Britton, W. B., Shahar, B., Szepsenwol, O., \& Jacobs, W. J. (2012). Mindfulness-based cognitive therapy improves emotional reactivity to social stress: Results from a randomized controlled trial. Behavior Therapy, 43, 365-380. doi:10.1016/j.beth.2011.08.006

Brosse, A. L., \& Craighead, L. W. (1999). Testing the mood-state hypothesis among previously depressed and never-depressed individuals. Behavior Therapy, 30, 97-115. doi:10.1016/S0005-7894(99)80048-3

Burcusa, S. L., \& Iacono, W. G. (2007). Risk for recurrence in depression. Clinical Psychology Review, 27, 959-985. doi:10.1016/j.cpr.2007.02 .005

Bylsma, L. M., Taylor-Clift, A., \& Rottenberg, J. (2011). Emotional reactivity to daily events in major and minor depression. Journal of Abnormal Psychology, 120, 155-167. doi:10.1037/a0021662

Cohen, L. H., Gunthert, K. C., Butler, A. C., O’Neill, S. C., \& Tolpin, L. H. (2005). Daily affective reactivity as a prospective predictor of depressive symptoms. Journal of Personality, 73, 1687-1714. doi:10.1111/j.00223506.2005.00363.x

Daley, S. E., Hammen, C., \& Rao, U. (2000). Predictors of first onset and recurrence of major depression in young women during the 5 years following high school graduation. Journal of Abnormal Psychology, 109, 525-533. doi:10.1037/0021-843X.109.3.525

Douma, M. (1991). The measurement of trait depression: Construction of the Dutch Dysfunctional Attitude Scale (A version) of Arlene Weissman. Meerssen, the Netherlands: St. Lois Marie Jamin.

Dozois, D. J. A., Covin, R., \& Brinker, J. K. (2003). Normative data on cognitive measures of depression. Journal of Consulting and Clinical Psychology, 71, 71-80. doi:10.1037/0022-006X.71.1.71

Dykman, B. M. (1997). A test of whether negative emotional priming facilitates access to latent dysfunctional attitudes. Cognition \& Emotion, 11, 197-222. doi:10.1080/026999397379999

Ehring, T., Fischer, S., Schnülle, J., Bösterling, A., \& Tuschen-Caffier, B (2008). Characteristics of emotion regulation in recovered depressed versus never depressed individuals. Personality and Individual Differences, 44, 1574-1584. doi:10.1016/j.paid.2008.01.013

Ehring, T., Tuschen-Caffier, B., Schnülle, J., Fischer, S., \& Gross, J. J. (2010). Emotion regulation and vulnerability to depression: Spontaneous versus instructed use of emotion suppression and reappraisal. Emotion, 10, 563-572. doi:10.1037/a0019010

Fava, G. A., Ruini, C., Rafanelli, C., Finos, L., Conti, S., \& Grandi, S. (2004). Six-year outcome of cognitive behavior therapy for prevention of recurrent depression. The American Journal of Psychiatry, 161, 1872-1876. doi:10.1176/appi.ajp.161.10.1872

Freedman, L. S., Graubard, B. I., \& Schatzkin, A. (1992). Statistica validation of intermediate endpoints for chronic diseases. Statistics in Medicine, 11, 167-178. doi:10.1002/sim.4780110204

Fresco, D. M., Heimberg, R. G., Abramowitz, A., \& Bertram, T. L. (2006). The effect of a negative mood priming challenge on dysfunctional attitudes, explanatory style, and explanatory flexibility. British Journal of Clinical Psychology, 45, 167-183. doi:10.1348/014466505X35137

Fresco, D. M., Rytwinski, N. K., \& Craighead, L. W. (2007). Explanatory flexibility and negative life events interact to predict depression symptoms. Journal of Social and Clinical Psychology, 26, 595-608. doi: 10.1521/jscp.2007.26.5.595

Fresco, D. M., Segal, Z. V., Buis, T., \& Kennedy, S. (2007). Relationship of posttreatment decentering and cognitive reactivity to relapse in major depression. Journal of Consulting and Clinical Psychology, 75, 447455. doi:10.1037/0022-006X.75.3.447

Guidi, J., Fava, G. A., Fava, M., \& Papakostas, G. I. (2011). Efficacy of the sequential integration of psychotherapy and pharmacotherapy in major depressive disorder: A preliminary meta-analysis. Psychological Medicine: A Journal of Research in Psychiatry and the Allied Sciences, 41, 321-331. doi:10.1017/S0033291710000826

Hamilton, M. (1960). A rating scale for depression. Journal of Neurology, Neurosurgery and Psychiatry, 23, 56-62. doi:10.1136/jnnp.23.1.56

Hollon, S. D., Stewart, M. O., \& Strunk, D. (2006). Enduring effects for cognitive behavior therapy in the treatment of depression and anxiety. Annual Review of Psychology, 57, 285-315. doi:10.1146/annurev.psych 57.102904 .190044

Jacobs, R. H., Reinecke, M. A., Gollan, J. K., Jordan, N., Silva, S. G., \& March, J. S. (2010). Extreme thinking in clinically depressed adolescents: Results from the Treatment for Adolescents with Depression Study (TADS). Behaviour Research and Therapy, 48, 1155-1159. doi: 10.1016/j.brat.2010.08.001

Jarrett, R. B., Minhajuddin, A., Borman, P. D., Dunlap, L., Segal, Z. V., Kidner, C. L., . . . Thase, M. E. (2012). Cognitive reactivity, dysfunctional attitudes, and depressive relapse and recurrence in cognitive therapy responders. Behaviour Research and Therapy, 50, 280-286. doi:10.1016/j.brat.2012.01.008 
Judd, L. L., Akiskal, H. S., Maser, J. D., Zeller, P. J., Endicott, J., Coryell, W., . . Keller, M. B. (1998). A prospective 12-year study of subsyndromal and syndromal depressive symptoms in unipolar major depressive disorders. Archives of General Psychiatry, 55, 694-700. doi: 10.1001/archpsyc.55.8.694

Judd, L. L., Akiskal, H. S., Zeller, P. J., Paulus, M., Leon, A. C., Maser, J. D., . . . Keller, M. B. (2000). Psychosocial disability during the long-term course of unipolar major depressive disorder. Archives of General Psychiatry, 57, 375-380. doi:10.1001/archpsyc.57.4.375

Kennedy, N., \& Paykel, E. S. (2004). Residual symptoms at remission from depression: Impact on long-term outcome. Journal of Affective Disorders, 80, 135-144. doi:10.1016/S0165-0327(03)00054-5

Kraemer, H. C., Wilson, G. T., Fairburn, C. G., \& Agras, W. S. (2002). Mediators and moderators of treatment effects in randomized clinical trials. Archives of General Psychiatry, 59, 877-883. doi:10.1001/ archpsyc.59.10.877

Kuyken, W., Watkins, E., Holden, E., White, K., Taylor, R. S., Byford, S., ... Dalgleish, T. (2010). How does mindfulness-based cognitive therapy work? Behaviour Research and Therapy, 48, 1105-1112. doi:10.1016/ j.brat.2010.08.003

Lethbridge, R., \& Allen, N. B. (2008). Mood induced cognitive and emotional reactivity, life stress, and the prediction of depressive relapse. Behaviour Research and Therapy, 46, 1142-1150. doi:10.1016/j.brat .2008.06.011

Lewinsohn, P. M., Allen, N. B., Seeley, J. R., \& Gotlib, I. H. (1999). First onset versus recurrence of depression: Differential processes of psychosocial risk. Journal of Abnormal Psychology, 108, 483-489. doi: 10.1037/0021-843X.108.3.483

Maldonado, G., \& Greenland, S. (1993). Simulation study of confounderselection strategies. American Journal of Epidemiology, 138, 923-936.

Martin, M. (1990). On the induction of mood. Clinical Psychology Review, 10, 669-697. doi:10.1016/0272-7358(90)90075-L

Mathers, C. D., \& Loncar, D. (2006). Projections of global mortality and burden of disease from 2002 to 2030. PLoS Medicine, 3(11), e442. doi:10.1371/journal.pmed.0030442

Miranda, J., Gross, J. J., Persons, J. B., \& Hahn, J. (1998). Mood matters: Negative mood induction activates dysfunctional attitudes in women vulnerable to depression. Cognitive Therapy and Research, 22, 363-376. doi:10.1023/A:1018709212986

Miranda, J., \& Persons, J. B. (1988). Dysfunctional attitudes are moodstate dependent. Journal of Abnormal Psychology, 97, 76-79. doi: 10.1037/0021-843X.97.1.76

Monroe, S. M., \& Harkness, K. L. (2005). Life stress, the "kindling" hypothesis, and the recurrence of depression: Considerations from a life stress perspective. Psychological Review, 112, 417-445. doi:10.1037/ 0033-295X.112.2.417

Mueller, T. I., \& Leon, A. C. (1999). Recurrence after recovery from major depressive disorder during 15 years of observational follow-up. The American Journal of Psychiatry, 156, 1000-1006.

Otto, M. W., Teachman, B. A., Cohen, L. S., Soares, C. N., Vitonis, A. F., \& Harlow, B. L. (2007). Dysfunctional attitudes and episodes of major depression: Predictive validity and temporal stability in never-depressed, depressed, and recovered women. Journal of Abnormal Psychology, 116, 475-483. doi:10.1037/0021-843X.116.3.475

Paykel, E. S., Ramana, R., Cooper, Z., \& Hayhurst, H. (1995). Residual symptoms after partial remission: An important outcome in depression. Psychological Medicine: A Journal of Research in Psychiatry and the Allied Sciences, 25, 1171-1180. doi:10.1017/S0033291700033146

Peeters, F., Berkhof, J., Rottenberg, J., \& Nicolson, N. A. (2010). Ambulatory emotional reactivity to negative daily life events predicts remission from major depressive disorder. Behaviour Research and Therapy, 48, 754-760. doi:10.1016/j.brat.2010.04.008

Petersen, T. J., Feldman, G., Harley, R., Fresno, D. M., Graves, L., Holmes, A., . . Segal, Z. V. (2007). Extreme response style in recurrent and chronically depressed patients: Change with antidepressant administration and stability during continuation treatment. Journal of Consulting and Clinical Psychology, 75, 145-153. doi:10.1037/0022-006X.75 .1 .145

Piet, J., \& Hougaard, E. (2011). The effect of mindfulness-based cognitive therapy for prevention of relapse in recurrent major depressive disorder: A systematic review and meta-analysis. Clinical Psychology Review, 31, 1032-1040. doi:10.1016/j.cpr.2011.05.002

Plaisier, I., Beekman, A. T. F., de Graaf, R., Smit, J. H., van Dyck, R., \& Penninx, B. W. J. H. (2010). Work functioning in persons with depressive and anxiety disorders: The role of specific psychopathological characteristics. Journal of Affective Disorders, 125, 198-206. doi: 10.1016/j.jad.2010.01.072

Rottenberg, J., Kasch, K. L., Gross, J. J., \& Gotlib, I. H. (2002). Sadness and amusement reactivity differentially predict concurrent and prospective functioning in major depressive disorder. Emotion, 2, 135-146. doi:10.1037/1528-3542.2.2.135

Rucci, P., Frank, E., Calugi, S., Miniati, M., Benvenuti, A., Wallace, M., . . . Cassano, G. B. (2011). Incidence and predictors of relapse during continuation treatment of major depression with SSRI, interpersonal psychotherapy, or their combination. Depression and Anxiety, 28, 955962. doi:10.1002/da.20894

Rush, A. J., Weissenburger, J., \& Eaves, G. (1986). Do thinking patterns predict depressive symptoms? Cognitive Therapy and Research, 10, 225-235. doi:10.1007/BF01173727

Segal, Z. V., Gemar, M., \& Williams, S. (1999). Differential cognitive response to a mood challenge following successful cognitive therapy or pharmacotherapy for unipolar depression. Journal of Abnormal Psychology, 108, 3-10. doi:10.1037/0021-843X.108.1.3

Segal, Z. V., Kennedy, S., Gemar, M., Hood, K., Pedersen, R., \& Buis, T. (2006). Cognitive reactivity to sad mood provocation and the prediction of depressive relapse. Archives of General Psychiatry, 63, 749-755. doi:10.1001/archpsyc.63.7.749

Shahar, B., Britton, W. B., Sbarra, D. A., Figueredo, A. J., \& Bootzin, R. R. (2010). Mechanisms of change in mindfulness-based cognitive therapy for depression: Preliminary evidence from a randomized controlled trial. International Journal of Cognitive Therapy, 3, 402-418. doi:10.1521/ ijct.2010.3.4.402

Silverman, J. S., Silverman, J. A., \& Eardley, D. A. (1984). Do maladaptive attitudes cause depression? Archives of General Psychiatry, 41, 28-30. doi:10.1001/archpsyc. 1984.01790120030005

Simons, A. D., Murphy, G. E., Levine, J. L., \& Wetzel, R. D. (1986) Cognitive therapy and pharmacotherapy for depression: Sustained improvement over one year. Archives of General Psychiatry, 43, 43-48. doi:10.1001/archpsyc.1986.01800010045006

Spitzer, R. L., Williams, J. B. W., Gibbon, M., \& First, M. B. (1990). User's guide for the Structured Clinical Interview for DSM-III-R: SCID. Washington, DC: American Psychiatric Association.

Stroud, C. B., Davila, J., Hammen, C., \& Vrshek-Schallhorn, S. (2011). Severe and nonsevere events in first onsets versus recurrences of depression: Evidence for stress sensitization. Journal of Abnormal Psychology, 120, 142-154. doi:10.1037/a0021659

Teasdale, J. D. (1988). Cognitive vulnerability to persistent depression. Cognition \& Emotion, 2, 247-274. doi:10.1080/02699938808410927

Teasdale, J. D., Moore, R. G., Hayhurst, H., Scott, J., Pope, M., \& Paykel, E. S. (2001). How does cognitive therapy prevent relapse in residual depression? Evidence from a controlled trial. Journal of Consulting and Clinical Psychology, 69, 347-357. doi:10.1037/0022-006X.69.3.347

ten Doesschate, M. C., Bockting, C. L. H., \& Schene, A. H. (2009). Adherence to continuation and maintenance antidepressant use in recurrent depression. Journal of Affective Disorders, 115, 167-170. doi: 10.1016/j.jad.2008.07.011

ten Doesschate, M. C., Koeter, M. W. J., Bockting, C. L. H., \& Schene, A. H. (2010). Health related quality of life in recurrent depression: A 
comparison with a general population sample. Journal of Affective Disorders, 120, 126-132. doi:10.1016/j.jad.2009.04.026

Thase, M. E., Simons, A. D., McGeary, J., Cahalane, J. F., Hughes, C., Harden, T., \& Friedman, E. (1992). Relapse after cognitive behavior therapy of depression: Potential implications for longer courses of treatment. The American Journal of Psychiatry, 149, 1046-1052.

Van der Does, A. J. W. (2002). Different types of experimentally induced sad mood? Behavior Therapy, 33, 551-561. doi:10.1016/S00057894(02)80016-8

Van der Does, A. J. W. (2005). Thought suppression and cognitive vulnerability to depression. British Journal of Clinical Psychology, 44, 1-14. doi: $10.1348 / 014466504 \times 19442$
Vittengl, J. R., Clark, L. A., Dunn, T. W., \& Jarrett, R. B. (2007). Reducing relapse and recurrence in unipolar depression: A comparative metaanalysis of cognitive-behavioral therapy's effects. Journal of Consulting and Clinical Psychology, 75, 475-488. doi:10.1037/0022-006X.75.3 .475

Weissman, A. N. (1979). The Dysfunctional Attitude Scale: A validation study. Dissertation Abstracts International, 40, 1389-1390. (198071511-001)

Received April 11, 2012

Revision received January 11, 2013

Accepted January 31, 2013

\section{Members of Underrepresented Groups: Reviewers for Journal Manuscripts Wanted}

If you are interested in reviewing manuscripts for APA journals, the APA Publications and Communications Board would like to invite your participation. Manuscript reviewers are vital to the publications process. As a reviewer, you would gain valuable experience in publishing. The P\&C Board is particularly interested in encouraging members of underrepresented groups to participate more in this process.

If you are interested in reviewing manuscripts, please write APA Journals at Reviewers@apa.org. Please note the following important points:

- To be selected as a reviewer, you must have published articles in peer-reviewed journals. The experience of publishing provides a reviewer with the basis for preparing a thorough, objective review.

- To be selected, it is critical to be a regular reader of the five to six empirical journals that are most central to the area or journal for which you would like to review. Current knowledge of recently published research provides a reviewer with the knowledge base to evaluate a new submission within the context of existing research.

- To select the appropriate reviewers for each manuscript, the editor needs detailed information. Please include with your letter your vita. In the letter, please identify which APA journal(s) you are interested in, and describe your area of expertise. Be as specific as possible. For example, "social psychology" is not sufficient-you would need to specify "social cognition" or "attitude change" as well.

- Reviewing a manuscript takes time (1-4 hours per manuscript reviewed). If you are selected to review a manuscript, be prepared to invest the necessary time to evaluate the manuscript thoroughly.

APA now has an online video course that provides guidance in reviewing manuscripts. To learn more about the course and to access the video, visit http://www.apa.org/pubs/authors/reviewmanuscript-ce-video.aspx. 